\title{
La representación de la mujer venezolana en redes sociales peruanas a través del término veneca
}

\section{The representation of Venezuelan women in Peruvian social networks through the veneca term}

\author{
Cesar Alberto Prado Ishuiza \\ Universidad Nacional Mayor de San Marcos, \\ Lima, Perú \\ cesar.prado2@unmsm.edu.pe \\ ORCID https://orcid.org/oooo-0oo2-3932-7989
}

\author{
Sandra Gladys Zavala Coronel \\ Universidad Nacional Mayor de San Marcos, \\ Lima, Perú \\ sandra.zavala@unmsm.edu.pe \\ orCID https://orcid.org/oooo-ooo1-9721-5558
}

\author{
Marco Antonio Lovón Cueva \\ Universidad Nacional Mayor de San Marcos, Lima, Perú \\ mlovonc@unmsm.edu.pe \\ ORCID https://orcid.org/oooo-00o2-9182-6072
}

\begin{abstract}
Resumen
En la actualidad latinoamericana, la migración venezolana se ha convertido en una problemática de índole política, económica, cultural y social. En ese sentido, en el territorio peruano, las olas migratorias han llevado a establecer medidas para atender a los venezolanos que huyen de la crisis en su país; por otra parte, las redes sociales han contribuido a formar una imagen estigmatizada del migrante. Este trabajo pretende analizar el discurso de los usuarios de las redes sociales respecto a la representación de la mujer venezolana a través del término peyorativo veneca. Metodológicamente, se recolectan comentarios en Facebook y Twitter durante el mes de junio de 2021. Finalmente, se concluye que la mujer venezolana es representada de forma negativa en base a las imágenes generalmente prejuiciosas que se les son atribuidas por los ciudadanos cibernautas peruanos.
\end{abstract}

Palabras clave: Lingüística migratoria, migración venezolana, estudios críticos del discurso, redes sociales, veneca.

\begin{abstract}
In Latin America today, Venezuelan migration has become a political, economic, cultural and social problem. In this sense, in the Peruvian territory, migratory waves have led to the establishment of measures to assist Venezuelans fleeing the crisis in their country; on the other hand, social networks have contributed to form a stigmatized image of the migrant. This paper aims to analyze the discourse of social network users regarding the representation of Venezuelan women through the pejorative term veneca. Methodologically, comments are collected on Facebook and Twitter during the month of June 2021. Finally, it is concluded that Venezuelan women are represented negatively based on the generally prejudiced images attributed to them by Peruvian cybernauts.
\end{abstract}

Keywords: Migratory linguistics, Venezuelan migration, critical discourse studies, social networks, veneca. 
La representación de la mujer venezolana en redes sociales peruanas a través del... Cesar Alberto Prado Ishuiza, Sandra Gladys Zavala Coronel y Marco Antonio Lovón Cueva

\section{Resumo}

Na América Latina de hoje, a migração venezuelana tornou-se uma questão política, econômica, cultural e social. Neste sentido, no Peru, as ondas de migração levaram ao estabelecimento de medidas para atender aos venezuelanos que fogem da crise no seu país; por outro lado, as redes sociais contribuíram para a formação de uma imagem estigmatizada do migrante. Este documento visa analisar o discurso dos utilizadores de redes sociais sobre a representação das mulheres venezuelanas através do termo pejorativo veneca. Metodologicamente, os comentários foram recolhidos no Facebook e Twitter durante o mês de Junho de 2021. Finalmente, conclui-se que as mulheres venezuelanas são representadas negativamente com base nas imagens geralmente preconceituosas que lhes são atribuídas pelos cibernautas peruanos.

Palavras-chave: Linguística Migratória, migração venezuelana, estudos críticos do discurso, redes sociais, veneca.

\section{Introducción}

El panorama político de Venezuela es cada vez más complejo. Este país se encuentra sumido en una crisis económica, política y social. El escenario de gobernabilidad del país se ve condicionado por cierres de fronteras y bloqueos económicos de países antes aliados. Venezuela presenta una elevada inflación, salida de multinacionales, cierre de medios de comunicación en oposición al régimen y un alto número de movilidad humana hacia el extranjero. La migración venezolana va en aumento. Según cifras de la ACNUR (2019), son más de tres millones de personas que se encuentran viviendo en el exterior, considerándose este éxodo como el más grande de la historia reciente de América Latina.

En el caso de la mujer venezolana, la situación es muy adversa: la ola migratoria ha generado que se trasladen con sus hijos, otras dejan a sus hijos a cargo de sus madres o familiares, hay mujeres que salen en condición de embarazo afectando sus condiciones de vida por la falta de salubridad y la carencia de medicamentos. Muchas llegan a países como Perú con escasos recursos y buscan albergue, alimentación, protección, y medicamentos (ACNUR, 2019). Por otro lado, la migrante venezolana a menudo, no solamente tiene que luchar por mejorar su calidad de vida, sino que también se enfrentan al estigma social que en su gran mayoría le han construido los medios de comunicación, estos, en su función primaria de informar, fomentan consigo estigmas e imaginarios sociopolíticos que condicionan los modos de vida. Las mujeres venezolanas y sus problemas, asimismo, no siempre aparecen como una temática de importancia en los medios

314 Lengua y Sociedad. Revista de Lingüística Teórica y Aplicada 
La representación de la mujer venezolana en redes sociales peruanas a través del... Cesar Alberto Prado Ishuiza, Sandra Gladys Zavala Coronel y Marco Antonio Lovón Cueva

de prensa, pues suelen estar invisibilizadas por las referencias que se hacen sobre los hombres venezolanos o la pluralidad en que se tratan a los migrantes bajo la voz venezolanos cuando son vistos como masa. Lo mismo sucede en las redes sociales, aunque en estas los cibernautas manifiestan y propalan obscenidades e improperios contra ellas de forma visible en el sentido de las cosifican como objetos sexuales frente a quienes idolatran su valor e inteligencia. Incluso, en el Twitter de canales de noticias se encuentran discursos que niegan que accedan al servicio de salud o reciban apoyo sanitario (Yalta \& Robles, 2021).

En el Perú, las mujeres venezolanas han enfrentado y enfrentan diversas dificultades; entre ellas, la falta de empleo (Condori et al., 2020). Según el INEI (2019), el sueldo de las mujeres venezolanas representa un $86,7 \%$ del ingreso de los varones (p.111). Esto conlleva a que se les dificulte acceder a todas sus necesidades básicas. Asimismo, los hombres tienen una mayor inserción laboral con el 96,5\% mientras que las mujeres un 89,9\%. Por ello, «[..] la tasa de desempleo en las mujeres se ubicó en $10,1 \%$, siendo 3 veces más que la de los hombres 3,5\%» (p.11). La mujer venezolana se encuentra bajo escenarios provenientes de una estigmatización laboral negativa, pues Blouin et al. (2020), afirman que existe la consideración de que a las personas venezolanas se les puede contratar como mano de obra barata. Muchas mujeres venezolanas trabajan fuera del sector formal en el país como amas de casa, vendedoras ambulantes, anfitrionas de restaurantes y clubes. Algunas han abierto negocios de venta de comida venezolana con carritos de hamburguesas, tequeños, empanadas. Otras pocas suben a los microbuses a vender golosinas. En el sector formal, algunas se ubican como secretarias, contadoras y doctoras. Para ello, han tenido que validar sus grados académicos, en los casos donde se le ha solicitado con el cumplimiento de esta condición. Casi nada se sabe sobre su salud mental, sus perspectivas de vida y su estigmatización.

El fenómeno de las migraciones ha sido analizado desde diferentes perspectivas. Las investigaciones sobre la migración venezolana se han desarrollado desde la economía, la sociología, la política; no obstante, aún los trabajos hechos desde la lingüística son escasos (Lovón et. al, 2021). Sobre la temática de mujeres venezolanas migrantes no abundan estudios. Por ejemplo, se rescata el trabajo de Ortiz (2021) respecto al imaginario de la mujer migrante venezolana en la prensa online colombiana. En su estudio se ve que muchas noticias tratan el tema de madre familia, seguido del papel profesional, del rol de hija, de trabajadora sexual, del rol delincuencial, del rol de esposa. Dicho estudio se trata de una investigación desde el ámbito de las Ciencias de la Comunicación. Desde el ámbito de la lingüística, 
La representación de la mujer venezolana en redes sociales peruanas a través del...

particularmente desde el análisis de los discursos, amerita realizar estudios sobre la forma en que son percibidas y las consecuencias que esto puede traer.

El presente artículo se centra en analizar las representaciones discursivas sobre la mujer venezolana en las redes sociales que se generan a través del uso de la voz peyorativa veneca. Este trabajo busca examinar las construcciones sobre la mujer venezolana en condición de migrante, evidenciando su situación de vulnerabilidad y discriminación existente en el país con miras a deconstruir imágenes que terminan por afectar su integración en la sociedad. .

Este trabajo presenta, dentro del marco teórico, conceptos relacionados con el análisis crítico del discurso; asimismo, se establece la relación que posee con el enfoque de la lingüística migratoria. Luego, se procede a indicar la metodología e instrumentos empleados en el presente estudio para la recolección de datos. Se realiza el análisis y explicación de la representación de la mujer venezolana en redes sociales; por último, se postulan los resultados de dicho análisis, llegando a conclusiones y reflexiones finales.

\section{Marco conceptual}

\subsection{Estudios Críticos del Discurso}

Los Estudios Críticos del Discurso (DPI) son la agrupación de teorías y principios de diversas disciplinas, especialmente sociales, culturales y políticas, que estudian el discurso en su nivel micro y macro, cuyo hilo conductor es la actitud crítica del investigador frente a los discursos que revelan diferencias sociales y que son legitimados por los miembros de una sociedad. Para estos investigadores, el discurso guía la acción social con el fin de favorecer intereses posicionados y privilegiados de unos frente a los intereses y expectativas de sectores sociales desfavorecidos (Pardo Abril, 2012, p. 3). Entre los sujetos inferiorizados se encuentran las mujeres y los migrantes, categorías que pueden interceptarse bajo la mirada social de ciertos grupos de personas y que motiva su estudio.

Los investigadores de los ECD tienen un compromiso con el reconocimiento de los otros marginados, por lo que cuestionan prácticas sociales y conocimientos hegemónicos. Para ello, analizan las formas en que se ejerce la dominación a través de los discursos en las diversas relaciones humanas, las cuales no siempre son justas y democráticas. Estas suelen tener repercusiones en la vida cotidiana de las personas, pues afectan emociones, decisiones y convivencias.

316 Lengua y Sociedad. Revista de Lingüística Teórica y Aplicada 
La representación de la mujer venezolana en redes sociales peruanas a través del... Cesar Alberto Prado Ishuiza, Sandra Gladys Zavala Coronel y Marco Antonio Lovón Cueva

Dentro de los estudios de cobertura mediática, los analistas de los ECD prestan atención al caso de la construcción de estigmas y estereotipos (Crandall y Coleman, 1992), hacia sujetos sociales como los migrantes. En el contexto de la migración, entre los migrantes y los residentes receptores, surgen relaciones de poder desequilibradas y particulares que terminan por crear estigmatizaciones sobre todo contra el migrante. Ello puede desencadenar, a su vez, tratos discriminatorios para quienes portan la marca estigmatizada.

Entre los ECD, incluso, se promueve el análisis de las diferencias de género entre las personas (Wheaterall, 2002). Los analistas del discurso observan el trato desigual que reciben las mujeres, por ejemplo, en diversas sociedades, en su representación discursiva. Los marcos de producción e interpretación del discurso muestran las relaciones de poder que se dan entre hombres y mujeres (Lazar, 2007), y otros grupos vulnerables. Por ello, se busca desmitificar las interacciones de género que se presentan en los discursos.

Entre los lingüistas, la preocupación por temáticas sociales ha permitido que se aúnen al esfuerzo por revelar las estrategias lingüísticas que se emplean para generar tratos desiguales entre las personas. El estudio del uso del lenguaje permite examinar el vocabulario, la fraseología, las metáforas, los campos semánticos como mecanismos que posibilitan la construcción de discursos, representaciones e ideologías. Actualmente, el trabajo, particularmente de sociolingüistas críticos, consiste en desvelar la jerarquía hegemónica que producen grupos sociales privilegiados por medio del lenguaje, como es el caso de las representaciones sociales que realizan hombres sobre las mujeres o la prensa machista contra las mujeres. Los diarios, por lo general, difunden estereotipos bajo etiquetas verbales e imágenes que la sociedad aprende y legitima como natural. Enmarcar la presente investigación bajo los ECD permite aunar esfuerzos interdisciplinarios como las indagaciones particulares que se realizan desde la sociología y la lingüística.

\subsection{Lingüística migratoria}

La lingüística migratoria, cuyos primeros estudios han sido germánicos, trata de una subdisciplina lingüística que forma parte de la Lingüística Aplicada y que ha presentado mayor auge durante los últimos años. Su importancia, según Estévez (2017, p. 34) radica en que la Lingüística Migratoria permite realizar una reflexión epistemológica acerca de los procesos de aculturación y rechazo por la que pasan los migrantes y la cual debe ayudar a mejorar la aplicación de políticas 
La representación de la mujer venezolana en redes sociales peruanas a través del...

migratorias para favorecer su integridad. Esta disciplina se concentra en la relación lengua-migración y discurso-migración.

Diversos investigadores prestan atención al fenómeno migratorio. La preocupación por los migrantes hace conocer su situación social, y los análisis desde la lingüística y el discurso exploran la forma en que el uso del lenguaje se emplea para generar representaciones sobre los migrantes. En general, los lingüistas preocupados por este tópico estudian y fomentan la integración social de los migrantes, sobre todo sus consecuencias. Esta perspectiva interesa en el contexto peruano porque el país se ha convertido en receptor de migraciones no solamente individuales, sino masivas. Para Moreno (2013, p. 75), interesa el estudio de las consecuencias lingüísticas producto de las migraciones dado que tienen efectos sobre aspectos sociales e individuales. Esto se ve reflejado en el Perú, con la creciente oleada de migración venezolana, pues el aspecto social ha repercutido en la ciudadanía peruana.

\subsection{Representaciones sociales}

Las representaciones sociales son las agrupaciones organizadas de saberes que están compartidas de forma social que se emplean para diseñar o percibir la realidad (Moscovici, 1979). Estas forman parte de la conciencia colectiva de los grupos sociales. Desde su dimensión psicosocial, permiten el ordenamiento y articulación de las interacciones y relaciones sociales. Desde una dimensión cognitiva, sirven como constructos mentales o marcos de referencias en la comprensión de la realidad (Jodelet, 1988, Mora, 2002). Este constructo conceptual que procede de la sociología permite conocer las formas en que determinados grupos sociales tienen sobre las personas desfavorecidas.

Socialmente, a diario, se realizan representaciones sobre las personas y colectivos: mujeres, hombres, homosexuales, indigentes, indígenas, migrantes, etc. Muchas de las formas en que se percibe al otro es negativa. En torno al migrante, las representaciones discursivas aparecen en boca de las personas en las calles, pero también a través de los medios de comunicación y las redes sociales en que aparecen construidos negativamente. Para Luhmann (2000), las redes sociales hoy en día se emplean como un espacio para conformar representaciones sociales sobre los migrantes. Al respecto, González Broquen (2011, p. 52) sostiene que la sociedad crea imágenes ficticias de los demás que no calzan siempre con la verdad. Tales representaciones se producen y reproducen por medio de los discursos y su consumo.

318 Lengua y Sociedad. Revista de Lingüística Teórica y Aplicada 
La representación de la mujer venezolana en redes sociales peruanas a través del... Cesar Alberto Prado Ishuiza, Sandra Gladys Zavala Coronel y Marco Antonio Lovón Cueva

\subsection{Migración venezolana en el Perú}

En cuanto a la migración venezolana, desde el año 2014, en el Perú, se produjo una importante oleada migratoria, ello se puede evidenciar en que cerca de cinco mil personas atravesaban la frontera peruana a diario, producto de la evidente crisis política-económica que vive el país. Los ciudadanos venezolanos optaron por buscar nuevos puntos de residencia; en primera instancia, para conseguir dinero y enviarlo a sus familiares quienes no pudieron emigrar; en segunda instancia, para mejorar su calidad de vida y volver a la situación en que se encontraban previo a la crisis de su país. El estado en el que se encuentran se debe a la migración forzada que han tenido que realizar para sobrevivir. Asimismo, debe precisarse que muchas veces el Perú no es el país de destino, aunque muchos migrantes permanecen por años en el país dada su estabilidad y comodidad, otros lo ven como un puente para migrar posteriormente hacia otros países, generalmente similares al suyo.

En el contexto de la migración, se fomentaron y difundieron estereotipos hacia los migrantes venezolanos, especialmente sobre las mujeres venezolanas, en muchos países de América Latina. En el caso de las mujeres, los estereotipos refieren a aspectos vinculados con la belleza, el físico, lo sexual, lo profesional, lo amical, que se propalan y afectan su aceptación y convivencia social en el país receptor. Blouin et al. (2020) mencionan:

Los estereotipos de género se presentan como descripciones generalizantes de las mujeres venezolanas referidas a sus características físicas, emocionales, intelectuales u otras. Se basan en falsas creencias exaltadas por los medios de comunicación o por mitos urbanos, y se reproducen en el ámbito laboral afectando las oportunidades de trabajo de estas mujeres. (p. 38)

Pese a ello, en los últimos años, los migrantes han logrado obtener una mayor estabilidad social, al menos en relación con la que tenían los primeros años, pues escuchar términos como xenofobia y discriminación eran muy frecuentes, y aunque la situación laboral y económica no es del todo favorable para ellos, en general, se ha producido una leve aceptación de parte de la sociedad peruana. En algunas interacciones con migrantes venezolanos, muchos han afirmado que han recibido algún tratamiento discriminatorio, pero en comparación con otros países de América Latina, el Perú es el que más los respeta. Incluso, se ve hoy en día familias, parejas y convivencias peruano-venezolanas. 
La representación de la mujer venezolana en redes sociales peruanas a través del...

\section{Metodología}

Esta investigación es de enfoque cualitativo y de nivel descriptivo. De acuerdo con Tamayo y Tamayo (2006), en este nivel se trabaja registrando y analizando los componentes del fenómeno estudiado. El presente trabajo analiza las representaciones a través del discurso que encierra la voz veneca que se le asignan a las mujeres venezolanas originadas con base en los actos que se le atribuyen. El corpus está conformado por 20 extractos lingüísticos que forman parte del discurso de los ciudadanos peruanos en torno al uso del término veneca. Estos se identifican como peruanos o se corrobora su nacionalidad en sus perfiles o algunos otros comentarios que revelan su identidad nacional.

Asimismo, en el marco de la pandemia mundial causada por la covid-19, donde es necesario el distanciamiento social, resulta demandante la aplicación de métodos que cumplan con este requisito. Por esta razón, en el presente trabajo se ha empleado la técnica de recolección de datos en entornos virtuales, que en este caso implica el recojo de comentarios a través de las redes sociales Twitter y Facebook. Para recolectar datos en Twitter (T), se optó por colocar en buscador la expresión «venecas Perú», en donde se encontraron posts relacionados con la forma en que es usada la voz veneca; asimismo, en la red social Facebook (F), se encontró una publicación de la página oficial del diario digital Trome que hacía alusión al mal uso del término veneca y del cual se extrajeron los comentarios que emitieron los cibernautas. Finalmente, la procedencia de los extractos se identifican con las siglas $\mathrm{T}$ si procede del Twitter y F si procede del Facebook.

\section{Análisis}

\subsection{Representación 1: "La veneca es un objeto sexual»}

Entre los discursos que representan a la mujer venezolana como objeto sexual se encuentran aquellos que la cosifican. Así, se ve que en (1) el cibernauta sarcásticamente señala que una persona es de una tendencia izquierda ('rojo') como el color que percibe después de haber tenido relaciones sexuales con una venezolana. Aquí, es considerada como una máquina sexual. Lo mismo ocurre con (2), donde el cibernauta convoca a tener coito con una extranjero. Sin embargo, su llamamiento parece invocar una violación. Los internautas varones muestran su virilidad contra las mujeres a través de las redes, porque es uno de los medios donde pueden maltratarla de forma abierta sin ser sancionados dada la ausencia de 
La representación de la mujer venezolana en redes sociales peruanas a través del... Cesar Alberto Prado Ishuiza, Sandra Gladys Zavala Coronel y Marco Antonio Lovón Cueva

control en este espacio. En (3), se observa que la mujer venezolana es considerada un recipiente de embarazos. Se cree que viene al Perú a tener hijos y obtener así la residencia. El internauta hace ver que son medio de fertilidad. Esta representación de objeto sexual encierra la voz veneca. Las personas transmiten y evocan la idea de que son instrumentos sexuales cuando usan esta palabra.

(1) «Es más rojo que poto de veneca después de echarse sus polvos» (T)

(2) «métanle huevo a la veneca» $(\mathrm{T})$

(3) «Pensé que era veneca en Perú, como estás solo vienen a preñarse» (T)

En los anteriores enunciados, se puede observar la sobresexualización de la mujer venezolana. Los discursos sirven para elaborar modelos normativos femeninos (Pastor, 2004, p. 219) que pueden construir imágenes de cosificación. Las mujeres se van viendo como cuerpos: «La nueva cultura hipersexual redefine el éxito femenino dentro del reducido marco del atractivo sexual» (Walter, 2010, p.23). Los cibernautas van representando a la mujer venezolana como objeto sexual negando su posición de sujeto.

\subsection{Representación 2: «La veneca es una trabajadora sexual»}

A través de la voz veneca, los cibernautas representan la imagen de la venezolana como prostituta. En (4) terminan indicando que el país es como una mujer fácil, como «veneca». Dicho de otro modo, la ven como una prostituta. En (15), se ve cree que una mujer venezolana es barata, que cuesta como la compra de un simple diario. Con la enumeración de 15 soles se evidencia el precio material que supuestamente cuesta. En (6) se sostiene que se dedican a la prostitución al nombrar que ejercen el oficio más antinguo de la vida. En (7), el cibernauta explicita uno de los lugares donde abunda la prostitución venezolana, que es el distrito de Los Olivos. En (8) se revela que ir para la veneca es ir a centro de prostitución. Dicho de otro modo, la voz veneca es sinónimo de prostituta o trabajadora sexual. En el uso, los hablantes hacen dicha asociación, por lo que el término invoca toda una representación social negativa.

(4) «No que Perú era fácil como una veneca» (T)

(5) «Perú 21, diario barato como veneca de 15 soles» (T)

(6) «Sea lo que sea, todas [las venecas] son iguales: ejercen la profesión más antigua y en todos los niveles» (F) 
La representación de la mujer venezolana en redes sociales peruanas a través del...

(7) «A las [venecas] de Plaza Norte no les afecta en nada» (F)

(8) «Ya está saliendo para la veneca». (F)

De acuerdo con lo anterior, los cuerpos de las mujeres son vistos con desigualdad y opresión (Maffía, 2011, p.211). El dominio patriarcal busca disciplinar los cuerpos de las mujeres para la disponibilidad sexual de los varones. Debe advertirse que en contextos de migración, las mujeres a veces acceden voluntariamente a trata o intercambios sexuales por dinero. Esta situación vulnera su condición. Aunque no ocurre con el grueso de migrantes venezolanas, los estereotipos pueden ocasionar que se generalice la idea de que todas las venezolanas se prostituyen, lo que merma nuevamente su imagen y aceptación en la sociedad. Al respecto, las connacionales critican ser comparadas con aquellas que pudieran ejercer el oficio de trabajadora sexual. Cobo (2015) afirma que la prostitución y la pornografía, así como la moda, la industria de la cirugía plástica, el exigente canon de belleza, se han convertido en formas represivas sobre el cuerpo de las mujeres. Ella terminan por condicionar su imagen, su comportamiento y la modelación de su cuerpo frente a la exigencia del trabajo sexual. Cabe añadir que en estos últimos años mujeres y hombres venezolanos obtienen ingresos de usuarios que se suscriben a su perfil de OnlyFans en donde promocionan imágenes y videos sexuales. Esto ha aumentado la percepción de prostitución sobre los migrantes en el Perú.

\subsection{Representación 3: "La veneca es una mujer delincuente»}

Entre otras representaciones, se presenta a la mujer venezolana como mujer delincuente. A ella se la asocia con ideas de robos. Por ejemplo en (9), el cibernauta señala que el país fue robado, y aunque no por una venezolana, cita la voz veneca para dejar en claro que ellas roban. Lo que hace en este caso a pesar de negar la responsabilidad del robo se hace una atribución entre robo y mujer migrante. En (10), en una asociación similar, el cibernauta prefiere quedarse en el país para estar al lado de una venezolana aunque le robe. El término veneca, entonces, sirve peyorativamente para marginar su imagen, que ha sido vinculada con acciones de robo y asalto.

(9) Robaron a Perú y a Brasil y no fue una veneca precisamente (T)

(10) Con ganas de estar en Perú para que me robe una veneca (T)

322 Lengua y Sociedad. Revista de Lingüística Teórica y Aplicada 
La representación de la mujer venezolana en redes sociales peruanas a través del... Cesar Alberto Prado Ishuiza, Sandra Gladys Zavala Coronel y Marco Antonio Lovón Cueva

Es decir, se observa que se le atribuye a la mujer venezolana el acto de robar. Según Cuevas (2018), la percepción de la inseguridad ciudadana se ha elevado a partir del incremento de migrantes venezolanos. Ante su llegada, hay un anhelo por encontrar medios seguros para diversas zonas limeñas (desde ciudadelas amuralladas hasta mayores rondas vecinales); posteriormente, con la llegada de venezolanos, se han originado odios, xenofobia e intolerancia, convirtiendo al migrante en la causa de los problemas sociales (p. 10-13). Entre los señalamientos de robos, no solo se acusa al hombre venezolano, sino también a la mujer venezolana, que aun habiendo casos reales atestiguados por la policía y difundido por los noticieros, se ha generalizado la percepción hacia los migrantes en general.

\subsection{Representación 4: "La veneca es una mujer interesada»}

Por otro lado, se concibe a la migrante venezolana como mujer interesada; es decir, aquella que puede conseguir dinero de manera sencilla ya sea engañando a hombres o aprovechando la favorable situación económica que ellos poseen. A continuación, se muestran discursos que revelan la representación de la mujer venezolana como interesada expresada en el término veneca.

(11) Más aburrida que veneca en Perú sin sacarle plata a un peruano (T)

(12) La veneca se casó por quedarse en Perú después de haber dicho que no le gustaba ese feo. (T)

En el enunciado (11), se expresa que resulta aburrido para una venezolana el no obtener dinero de un peruano, por lo que se toma esta acción como habitual en ellas. Los peruanos en sus discursos suelen manifestar que son aprovechadas, que no les gusta trabajar, sino que fácilmente quieren acceder al dinero. Esta manera de pensar ha sido trasladada de las conductas de los hombres venezolanos, quienes son percibidos como personas que buscan a mujeres, e incluso hombres peruanos, para obtener dinero, muchas veces a cambio de relaciones sexuales. Tal vez es una conducta negativa compartida entre ambos géneros, pero que al generalizarse ocasiona percepciones injustas en migrantes que contradicen los malos hábitos. Finalmente, en (12), se alude que, a pesar de un rechazo por el aspecto físico de un peruano, una venezolana se casó con él para mantener su estancia en el país, entonces existe el reflejo de un acto interesado. En otras palabras, parece realizarse un acto no deseado, con el fin de conseguir algo provechoso a cambio. Este es uno de los casos que se encuentra en las redes sociales 
La representación de la mujer venezolana en redes sociales peruanas a través del...

y que se ha escuchado entre los pobladores peruanos. Se asume que las mujeres venezolanas no se enamoran de los peruanos, sino que sus propósitos son otros. A veces, incluso se ha atestiguado que tienen relaciones extramaritales con connacionales, mantienen a otras parejas, o no han obtenido el divorcio, por lo que se escucha términos como monta cachos, para indicar que las mujeres, así como los hombres venezolanos, son infieles. Con el término veneca, se consigue elaborar representaciones de mujer delincuente y mujer interesada.

\subsection{Representación 5: "La veneca es una robamaridos»}

Asociada a la representación anterior, se tiene aquella que la percibe como quita marido, dado que se las responsabiliza de la destrucción de parejas, familias y hogares. Para el CAPS (s.f.), en las vías públicas se utilizan expresiones xenofóbicas en el uso del término «veneca» de manera peyorativa por varones y mujeres, junto a insultos y reproches por su presencia en el país; [acompañados de] acusaciones de ser «roba marido», «roba trabajos» (p. 3). En las redes sociales, los cibernautas mencionan este adjetivo, frecuentemente, al hacer referencia a las mujeres venezolanas. Esto se observa en los siguientes discursos:

(13) «Veneca en Perú tipo casual: -No sabía qué ponerme y me puse a robar maridos» $(\mathrm{T})$

(14) "Más venezolana que la veneca que te robo un marido en Perú» (T)

(15) «Cómo es posible eso de que eres veneca en Perú y no te has robado un marido ya» $(\mathrm{T})$

En (13) el cibernauta señala que es habitual que las venezolanas establezcan relaciones con hombres casados; por eso, crea una intertextualidad al decir «No sabía qué ponerme y me puse a robar maridos», para hacer ver que la acción realizada resulta tan común. Por otro lado, en (14), la cibernauta afirma que el hecho de ser de nacionalidad venezolana presupone que ya debe haber robado un marido. En el Perú, las mujeres acusan a las extranjeras de la separación de parejas y matrimonios. En (15), se refuerza que el calificativo de robamaridos a las mujeres venezolanas residentes en Perú ha resultado tan marcado que, si una de ellas no ha realizado la acción de tener una relación amorosa con un hombre casado, no es creíble que se trate de una mujer venezolana. Cabe precisar que el comportamiento que han manifestado algunas féminas venezolanas en el Perú ha generado entre los peruanos que a ellas se les atribuyan el calificativo de robamaridos y que

324 Lengua y Sociedad. Revista de Lingüística Teórica y Aplicada 
La representación de la mujer venezolana en redes sociales peruanas a través del... Cesar Alberto Prado Ishuiza, Sandra Gladys Zavala Coronel y Marco Antonio Lovón Cueva

se haya extendido la calificación a todas las migrantes. El uso de la voz veneca, en este caso, es sinónimo de tal atribución.

Finalmente, la representación bastante frecuente de robamaridos a la mujer venezolana, ha ocasionado mofa entre la población peruana, pues de acuerdo con el siguiente discurso, existe un disfraz de veneca robamarido y este ha tenido bastante demanda entre los ciudadanos peruanos. Dicho de otra manera, se materializa en un disfraz o atuendo la acción de quitar a un esposo.

\section{(16) «Disfraz de veneca robamaridos repunta en Perú» (T)}

Este tipo de discursos genera recelos entre las mujeres peruanas. Ellas acusan en forma de reclamo los hábitos atribuidos a las migrantes. Dada la generalización por los estereotipos negativos, el grado de desconfianza aumenta hacia las venezolanas migrantes, quienes responden a los ataques; algunas incluso se han enfrentado físicamente a peruanas. Llamarlas robamaridos abiertamente es una forma descortés en el trato, pues ocasiona desplante, rechazo y aislamiento.

\subsection{Representación 6: "La veneca es el estándar de belleza»}

Desde su llegada al Perú, la presencia de las venezolanas ha creado diversos estereotipos en la sociedad peruana; entre ellos, la belleza que simbolizan. De manera fáctica, se ha observado que poseen rasgos muy marcados que logran que, de cierta forma, se les identifique en relación con la nacionalidad que poseen; es decir, al observar con detenimiento a una fémina, por ciertos patrones estéticos que se le atribuyen, frecuentemente, ocasiona que se intuya su país de natalidad. Se presenta el siguiente discurso:

(17) «Descubrí que soy racista, porque vi a la de Perú y pensé que era veneca». $(\mathrm{T})$

Como se puede observar, en (17), el escritor de dicho post reconoce que al identificar ciertos rasgos faciales o corporales de una mujer parecida a una venezolana, creyó que lo era, cuando se trataba de una peruana. Cuando una mujer está arreglada y bonita, piensan que se trata de una mujer extranjera, haciendo pensar que las peruanas son descuidadas. Esto ha ayudado a empoderar a las mujeres extranjeras, en el sentido de que algunas afirman que son más bonitas que las residentes, e incluso se perciben como superiores atractiva y físicamente. 
La representación de la mujer venezolana en redes sociales peruanas a través del...

Desde hace décadas, se reconoce la belleza que poseen las mujeres venezolanas. Hurtado (2018) afirma que en Venezuela, hay una obsesión por la belleza femenina. Asimismo, señala que «específicamente la mujer en cuanto que para mejorar su presencia de belleza tiene que someterse a un ritual de limpieza corporal de cara a su presentación en público» (p. 202), lo que fundamenta el éxito de ellas en certámenes de belleza internacionales y el reconocimiento por la belleza que poseen.

Durante el 2019 en el Perú, debido al certamen mundial de belleza, se afianzó esta afirmación. Se puede mostrar ello en los siguientes discursos:

(18) «La miss Perú tiene pinta de veneca». (T)

(19) «Miss Perú tenía más pinta de veneca que peruana». (T)

(20) "Es más que sabido que la miss Perú es una veneca nacionalidad, esa belleza no es autóctona del país inca». (T)

De este modo, se observa en (18), (19) y (20) que existe una suposición sobre la nacionalidad de la miss Perú, pues al mencionar tiene pinta de veneca o tiene más pinta de veneca en estos Twitters hace implicar que presenta las características de belleza de mujer venezolana y que se trataría de una, dado que se cuestiona la belleza peruana por la creencia deslumbrante de la belleza venezolana. En el país, algunas mujeres venezolanas han abierto centro de bellezas, modelaje y pasarela para niñas y jóvenes peruanas y también venezolanas, para enseñarles formas de participar y modelar en certámenes de belleza. Hay un público de mujeres que fomentan este circuito laboral.

En este caso, la voz veneca parece asociarse con un discurso más positivo, pues se destaca su apariencia y atractivo. Esto puede permitirnos señalar que dicho término no siempre se emplea de forma negativa, sino que se recrea en la interacción comunicativa.

\section{Conclusiones}

La globalización y las migraciones hacen repensar las relaciones entre grupos sociales, discursos y territorios nacionales. En la época actual, se han multiplicado las movilizaciones sociales, algunas producto de una migración forzada, de las cuales se hablan y tratan en los medios virtuales. Los cibernautas intercambian símbolos y discursos contra el otro percibido como amenaza. Uno de los tópicos discursivos en redes sociales es la migración venezolana. En el Perú, como se ve

326 Lengua y Sociedad. Revista de Lingüística Teórica y Aplicada 
La representación de la mujer venezolana en redes sociales peruanas a través del... Cesar Alberto Prado Ishuiza, Sandra Gladys Zavala Coronel y Marco Antonio Lovón Cueva

en la presente investigación, se encuentran representaciones negativas y discursos xenófobos contra las mujeres venezolanas, que menoscaban su imagen y presencia en territorio peruano. Muchas de las formas en que son tratadas responden a prejuicios generalizados.

A partir del análisis de las representaciones discursivas bajo la voz veneca, se puede concluir que las mujeres venezolanas son construidas de forma estigmatizada. A través de este término, la mujer venezolana migrante es asociada con temas de sexualidad, prostitución y criminalización, apenas se encuentra una representación de aceptación, pero, aparentemente, condicionada a un aspecto biológico, que es la atribución a belleza. Según Arévalo y Ruiz (2019), «la 'veneca', como mujer, está asociada a la prostitución y a 'robar maridos'. El uso de esta palabra siempre está en clave de amenaza de quitar algo a través de la invasión del territorio» (p.163). Dicho de otro modo, la voz peyorativa veneca recrea representaciones adversas para las mujeres venezolanas. Sin embargo, más allá de este trabajo realizado, cabe añadir que la voz también va cobrando una connotación distinta cuando una peruana llama a una venezolana como «Ella es mi amiga veneca», y no siente ofensa; o cuando una venezolana «bautiza» a una peruana llamándola veneca, por algún grado de familiaridad o amicalidad. Lo que muestra que el signo lingüístico no es estático, sino más bien responde a múltiples situaciones sociales.

Creemos que este trabajo se enmarca dentro de los ECD en tanto que reúne los estudios discursivos desde la sociología y la lingüística. En la investigación, se tomó el concepto de representación y se vinculó con el análisis del discurso crítico. De forma ecléctica, consideramos que ello contribuye con cuestionar el tratamiento desigual que reciben las mujeres migrantes. Asimismo, el trabajo se sitúa como una preocupación de la agenda de la Lingüística Migratoria, en tanto que se ocupa de la relación entre lenguaje y migración. Los estudios que van abordando de forma específica esta interrelación van siendo agrupados en esta disciplina, junto con otros que centran su atención en el migrante y el signo lingüístico, así como la planificación de políticas lingüísticas migratorias.

En términos reflexivos podemos señalar que las representaciones discursivas vistas que se manifiestan en las redes sociales sobre las mujeres migrantes venezolanas generan injusticia y falta de respeto, y muestran relaciones de poder de exclusión y dominación en el territorio peruano. Por eso, es importante realizar un seguimiento crítico de la representación y del manejo de los recursos lingüísticos que hacen las redes sociales con el fin de denunciar los discursos que fomentan el 
La representación de la mujer venezolana en redes sociales peruanas a través del...

odio hacia la migración y censurar las atribuciones peyorativas prejuiciosas. Hace falta, asimismo, explorar qué piensan las mujeres venezolanas de los discursos descritos y de cómo ellas perciben a las mujeres peruanas. Revisar los discursos negativos y positivos que tienen sobre las peruanas es una tarea pendiente si se quiere discutir la forma en que se usa el lenguaje para hacer representaciones sobre los diversos grupos sociales y revelar más que un enfrentamiento, una búsqueda por un discurso común que favorezca la integración social.

Agradecimientos

Los autores agradecen los alcances brindados por el profesor Marco Lovón, cuyos consejos iniciaron a darle forma y sentido al artículo, y que terminamos por presentarlo en conjunto como parte del grupo de investigación en que participamos, dada la reescritura, los aportes, y las explicaciones en el contenido.

Financiamiento

Este artículo se ha elaborado en el marco del proyecto de investigación E21030371 del Vicerrectorado de Investigación y Posgrado de la Universidad Nacional Mayor de San Marcos, RR 005753-2021-R/UnMSM.

\section{Conflicto de intereses}

Los autores no presentan conflicto de interés.

\section{Referencias bibliográficas}

ACNur (Alto Comisionado de las Naciones Unidas para los Refugiados) (2019). Situación en Venezuela. https://bit.ly/3yBwchR

Arévalo, G., y Ruiz, A. (2019). Revictimización de la movilidad humana en la prensa boyacense. Diálogos de Saberes, (51), 153-174. https://doi. org/10.18041/0124-0021/dialogos.51.2019.5877

Blouin, C. et al. (2020). Las mujeres migrantes y refugiadas venezolanas y su inserción en el mercado laboral peruano: dificultades, expectativas y potencialidades. Lima: PUCP. https://bit.ly/3rueqPY

328 Lengua y Sociedad. Revista de Lingüística Teórica y Aplicada 
La representación de la mujer venezolana en redes sociales peruanas a través del... Cesar Alberto Prado Ishuiza, Sandra Gladys Zavala Coronel y Marco Antonio Lovón Cueva

CAPs. (s. f.). Diagnóstico sobre riesgos psicosociales de violencia de género, trata de personas y explotación sexual. Proyecto Integrando Horizontes, 3. https:// bit.ly/3Bwu8cP

Cobo, R. (2015). El cuerpo de las mujeres y la sobrecarga de sexualidad. La Coruña: Universidad de La Coruña. https://bit.ly/3jAaV $3 y$

Condori, M. et al. (2020). Éxodo venezolano, inserción laboral y discriminación social en la ciudad de Huancayo, Perú. Espacios, 41, 72-83. https://bit. ly/3hQuqoJ

Crandall, Ch. y Coleman, R. (1992). AIDS-related stigmatization and the disruption of social relationships. Journal of Social and Personal Relationships, 9, 163-177. https://bit.ly/3ytNiPd

Cuevas, E. (2018). Reconfiguración social: entre la migración y la percepción inseguridad en Lima, Perú. Revista Latinoamericana de Estudios de Seguridad, 23, 73-90.

Defensoría del Pueblo. (2020). Personas venezolanas en el Perú. Análisis de su situación antes y durante la crisis sanitaria generada por el Covid-19. https:// bit.ly/3jCLhLB

Estévez, M. (2017). Lingüística Migratoria e Interpretación en los Servicios Públicos: La comunidad gallega en Alemania. Frank \& Timme GmbH.

Gonzalez Broquen, X. (2011). Hacia una categorización del poder mediático: poder representativo, meta-poder y anti-poder. Mediaciones sociales, 8, pp. 47-68. https://bit.ly/3notGeN

Hurtado, S. (2018). Obsesión por la belleza femenina en Venezuela. Espacio Abierto, 27(2), 191-208. https://bit.ly/3nhqAнh

INEI (Instituto Nacional de Estadística e Informática). (2019). Condiciones de vida de la población venezolana que vive en el Perú. Resultado de la encuesta dirigida a la población venezolana. Lima. https://bit.ly/3zJiw5q

Jodelet, D. (1988). La representación social: fenómenos, conceptos y teoría. En S. Moscovici (Eds.). Psicología social II. Pensamiento y vida social (pp. 469-494). Paidós.

Lazar, M. (2007). Feminist Critical Discourse Analysis: Articulating a Feminist Discourse.

Critical Discourse Studies, 4(2), 141-164.

Lovón, M.-A., García, A.-M., Yogui, D., Moreno, D. y Reyna, B. (2021). La migración venezolana en el Perú: el discurso de la explotación laboral. Lengua y 
La representación de la mujer venezolana en redes sociales peruanas a través del...

Cesar Alberto Prado Ishuiza, Sandra Gladys Zavala Coronel y Marco Antonio Lovón Cueva

Sociedad, 2o(1), 189-220. http://revista.letras.unmsm.edu.pe/index.php/ls/ article/view/2209

Luhmann, N. (2000). La realidad de los medios de masas. Barcelona: Anthropos.

Maffía, D. (2010). Tecnología y control social de los cuerpos sexuados. III Congreso Iberoamericano de Filosofía de la Ciencia y de la Tecnología. Buenos Aires, Argentina. https://bit.ly/3muxjrX

Mora, M. (2002). La teoría de las representaciones sociales de Serge Moscovici. Athenea Digital, 2, 1-25. https://bit.ly/3isnvSo

Moreno, F. (2013). Lingüísticas y migraciones hispanas. Lengua y migración, 5(2), 67-89.

Moscovici, S. (1979). El psicoanálisis, su imagen y su público. Huemul.

Ortiz Acevedo, M. (2021). Des-ubicación mediática: el imaginario de la mujer migrante venezolana en la prensa online colombiana. Sistema Nacional de Bibliotecas Rafael Garcia Herreros. https://bit.ly/3wrBqLJ

Pardo Abril, N. (2012). Análisis crítico del discurso: Conceptualización y desarrollo. Cuadernos de Lingüística Hispánica, 19, 41-62.

Pastor, R. (2004). Cuerpo y género: representación e imagen corporal. En E. Barberá y I. Martínez Benlloch (Coords.), Psicología y Género (pp. 217-239). Pearson.

Yalta, E., \& Robles, M. (2021). Migración y redes sociales: discursos sobre la ayuda social hacia los migrantes venezolanos en contexto de pandemia por los usuarios peruanos en Twitter. Conexión, (16), 87-110. https://doi.org/10.18800/ conexion.202102.004

Walter, N. (2010). Muñecas vivientes. El regreso del sexismo. Turner. Weatherall, A. (2002). Gender, language and discourse. Routledge.

330 Lengua y Sociedad. Revista de Lingüística Teórica y Aplicada 
La representación de la mujer venezolana en redes sociales peruanas a través del... Cesar Alberto Prado Ishuiza, Sandra Gladys Zavala Coronel y Marco Antonio Lovón Cueva

\section{Trayectoria académica de los autores}

\section{Cesar Alberto Prado Ishuiza}

Estudiante de séptimo ciclo de la Escuela Profesional de Lingüística de la Universidad Nacional Mayor de San Marcos. Sus inclinaciones académicas están dirigidas hacia la etnolingüística, lexicografía-lexicología y revitalización de lenguas, con especial énfasis en la zona norte del territorio peruano. Forma parte del grupo de investigación Lenguas y Filosofías del Perú (LFP).

\section{Sandra Gladys Zavala Coronel}

Estudiante de séptimo ciclo de la Escuela Profesional de Lingüística de la Universidad Nacional Mayor de San Marcos. Sus inclinaciones académicas están dirigidas hacia la Lingüística Cognitiva, Psicolingüística y la enseñanza de segunda lengua; inglés. Forma parte del grupo de investigación Lenguas y Filosofías del Perú (LFP).

\section{Marco Antonio Lovón Cueva}

Lingüista y politólogo. Es doctor y magíster en Lingüística por la Pontificia Universidad Católica del Perú (PUCP). Es licenciado en Lingüística por la Universidad Nacional Mayor de San Marcos (UNMSM). Y bachiller en Lingüística y Ciencia Política por la misma universidad. Sus intereses investigativos se centran en las áreas de la Sociolingüística y en temas de Relaciones Internacionales y Diplomacia. Marco Lovón es docente en la UnMSM, la PUCP y la Fundación de la Academia Diplomática del Perú (ADP). Forma parte del grupo de investigación Lenguas y Filosofías del Perú (LFP). 